\title{
Education Amidst Pandemic: A Meta-Study on Parents' Experiences
}

\author{
Argie Anthony C. Inciso \\ argiea.inciso@lnu.edu.ph \\ Leyte Normal University, P. Paterno St., Tacloban City, 6500, Philippines
}

\begin{abstract}
Covid-19 pandemic affected the educational system. The education framework adapted the situation by changing from traditional to distance learning. Parents faced challenges and difficulties with the demands of the new normal in education. This study aims to find out the experiences of parents in supporting their children's education during pandemic. This is a qualitative meta-analysis research. Meta-study design was used in analyzing research findings and processes concerning parents' experiences in supporting their children's education during pandemic. Five published research articles were selected based on a selection criteria and were systematically reviewed. Meta-data, meta-method, and meta-theory were presented based on the analysis of the studies. It was found out that parents' struggles include disruption of schedule, inadequate skills to support learning, and financial difficulties.
\end{abstract}

Keywords: Education; Covid-19; Pandemic; Parents’ Experiences

\section{Introduction}

When Covid-19 pandemic started, schools were closed and the delivery of teaching-learning process changed from traditional to distance learning. With this, education faced different challenges to achieve academic success among students (Reimers \& Schleider, 2020). Indeed, educational system should be flexible (Daniel, 2020). However, there are many factors to consider as the educational system changed from traditional to distance learning (Angnoletto \& Queiroz, 2020; Crawford et al., 2020; Vlachopoulos, 2020). Thus, there should be changes on our goals in education in response to the current situation (Schleicher, 2020).

An adaptive educational framework should be one of the priorities of the government to address the sudden shift in education (Reimers \& Schleider, 2020). Technology would be the key factor to the success of distance learning (Bloom, Reid, \& Cassady, 2020).Teachers should be equipped with the necessary skills to address the educational consequences of ensuring the continuation of quality education during pandemic (Zhu \& Liu, 2020). Curriculum framework should adapt the current situation to contextualize learning experiences (Daniel, 2020; Gonzalez, 2020, Toquero, 2020; Zhu \& Liu, 2020). Thus, the quality of education from traditional to distance learning really differs a lot (Gonzalez et. al, 2020; Grover et. al, 2020).

The education sectors has been adapting through collaboration (Harris, 2020). Collaboration is essential in facing the new normal in education (Tria, 2020). Communication between students, parents, teachers, school, and community is very important in attaining academic success (Daniel, 2020). Indeed, community involvement is necessary in education during pandemic (Bloom, Reid, \& Cassady, 2020). According to Reimers and Schleider (2020), parents are struggling in supporting distance learning and in collaborating to teachers and schools. With the closure of schools, parents have to be flexible in balancing 
their responsibilities (Garbe, 2020). They have to carefully adjust their time for work, parenthood, helping their children in school tasks, and the like. Parents should allot time, acquire skills and knowledge, and use available resources to help their children learn (Burgess \& Sievertsen, 2020; Garbe et al., 2020). As presented by Reimers and Schleicher (2020), providing support to parents to carry out distance learning to students is critical. Motivating their children to do school work is another challenge faced by parents too (Garbe, 2020). These affect the mental health of students and parents (Karalis \& Raikou, 2020; Zhu \& Liu, 2020). In contrast, Garbe et al. (2020) found out that some parents are satisfied with the initiatives from schools. With the underlying factors, inequalities in education is very evident (Aristovnik et. al, 2020; Bonal \& Gonzales, 2020; Marioni, Van't Land, \& Jensen, 2020). With the disruptions caused by the pandemic, researches to improve educational systems are necessary (Allen, Rowan, \& Singh, 2020; Moorhouse, 2020).

\subsection{Epistemological Issues}

With the emergence of the pandemic, the educational system has to adapt. The mode of instruction changed from traditional to distance learning. This happened with just a short period of time without any preparations. Thus, there was an uncertainty if the new methods will be effective to children's learning. Many difficulties and challenges happened. With this, parents were confused and pressured. Thus, the researcher would like to emphasize that based on the gathered data coming from the results of the different studies. There were plenty of biases. Physical, mental, emotional, social, financial stress are very evident. These strong feelings would affect the quality of responses coming from parents. However, the researcher believe that this should be supported with research findings that would prove the latter. Most responses were negative towards the implementation of the new normal set up for education. But there are already interventions coming from the educational sectors to meet these demands. Also, the representation of the parents vary in terms of socio-economic background, educational attainment, stress tolerance, number of children, capabilities of children, and the like. Also, it should be noted that the results of the different studies came from different countries experiencing different situations in the implementation of education during pandemic.

\subsection{Research Question}

It has been observed that there are many complains on how the educational system is being conducted to continue the education program of children. Thus, the researcher would like to find out the experiences of parents in the implementation of education during this Covid-19 pandemic.

\section{Methodology}

This study is a qualitative meta-analysis research. The researcher used Paterson et al. (2001) metastudy design consisting of meta-data, meta-method, and meta-theory. Thus, this study utilized results and processes from published researches concerning parents' experiences during pandemic (Timulak, 2014).

\subsection{Selection and Appraisal of Primary Studies}

This study used five research articles that focused on parents' experiences during pandemic. Three researches are from the ScienceDirect database and two researches are from SpringerLink database. 
Table 1. The primary studies utilized in the meta-study.

\begin{tabular}{ll}
\hline Research Articles & Database \\
\hline $\begin{array}{l}\text { A Survey Of Parents Of Children Attending The Online Classes During The Ongoing } \\
\text { COVID-19 Pandemic (Grover et al., 2020) }\end{array}$ & ScienceDirect \\
\hline $\begin{array}{l}\text { Parenting Activities And The Transition To Home-Based Education During The } \\
\text { COVID-19 Pandemic (Lee et al., 2021) }\end{array}$ & ScienceDirect \\
\hline $\begin{array}{l}\text { Barriers To Distance Learning During The COVID-19 Outbreak: A Qualitative } \\
\text { Review From Parents' Perspective (Abuhammad, 2020) }\end{array}$ & ScienceDirect \\
\hline $\begin{array}{l}\text { A Survey Of Parents Of Children Attending The Online Classes During The Ongoing } \\
\text { COVID-19 Pandemic (Dong, Cao, \& Li, 2020) }\end{array}$ & SpringerLink \\
\hline $\begin{array}{l}\text { The Impact Of Lockdown On The Learning Gap: Family And School Divisions In } \\
\text { Times Of Crisis (Bonal \& González, 2020). }\end{array}$ & SpringerLink \\
\hline
\end{tabular}

The following studies were subjected to a systematic review based on the purpose of the study and quality of findings. Grover et al. (2020); Lee et al. (2021); Dong, Cao, and Li (2020); and Bonal and González (2020) used an online survey. Thus, their studies are quantitative. They used descriptive representations of the data. However, the researcher used these studies because of the considerable number of respondents for each study that could give a comprehensive understanding on the experiences of the parents. Abuhammad (2020) used qualitative analysis to the dialogues of parents in social media. The researcher found this very useful to understand deeper the sentiments of parents by not just focusing on quantitative results.

\subsection{Data Analysis}

Qualitative content analysis was used in identifying the underlying themes in the presentation of the meta-data. The researcher started the initial stage by content coding. It was followed by themeing the data. Themes were made by understanding the relationships of the different content codes. For meta-method, the researcher analyzed the research questions, researchers, settings and the sampling procedures of the different studies. The researcher made a summary to understand deeper the context of the studies. The researcher used a theory in interpreting the underlying context of the studies in meta-theory.

\section{Results and Discussion}

As suggested by Paterson et al. (2001), three components are presented namely meta-data, metamethod, and meta-theory.

\subsection{Meta-data}

There were three major themes found by the researcher- (1) Disrupted Schedule, (2) Inadequate Skill, and (3) Financial Difficulty.

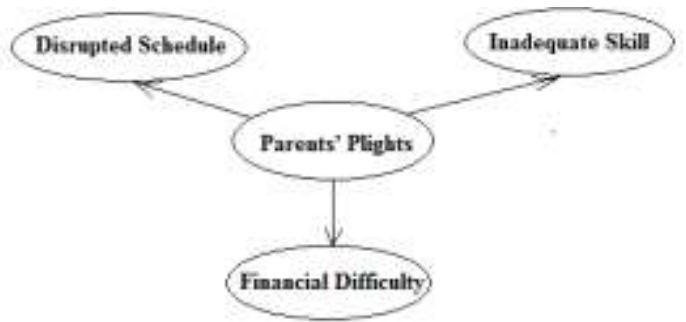

Figure 1. Parents' plights with its themes-disrupted schedule, inadequate skill, and financial difficulty. 
Theme 1. Disrupted Schedule

It was found out in the studies that parents have to be flexible. Thus, they need to manage their time for work, parenthood, and in assisting their children in doing school tasks (Abuhammad, 2020; Dong, Cao, \& Li, 2020; Grovel et al., 202; Lee et al., 2021)

Theme 2. Inadequate skill

This pertains to the pedagogical knowledge of parents in supporting their children in their school tasks. This is influenced by their educational attainment and technical knowledge in handling technology (Abuhammad, 2020; Bonal \& González, 2020; Dong, Cao, \& Li, 2020; Lee et al., 2021).

Theme 3. Financial Difficulty

With the demands of distance learning, additional financial responsibilities occurred (Abuhammad, 2020; Bonal \& González, 2020; Lee et. al, 2021). This may refer to purchasing and maintaining the needed technology for distance learning.

\subsection{Meta-method}

The different researches examined the experiences of parents in supporting their children in the implementation of distance learning during the pandemic. However, the studies have different sampling procedures. The questions presented on the online surveys vary. Thus, the researcher is aware of the differences towards the subject of interest. Also, the researchers are from different countries with different experiences during the pandemic. The findings of their studies are influenced by the different settings. The researchers differ in their field of profession and their focus of the study. Quantitative and qualitative results were utilized based on their sampling procedure. The appropriateness of their sampling techniques were aligned to their research questions. However, the researcher is aware that the representation of the respondents and participants is limited. Finally, the different studies, though different with some aspects, share a common goal of understanding the underlying factors in the struggles of parents during the time of pandemic. Their findings are relevant for the study.

\subsection{Meta-theory}

According to Siemens (2005), learning may came from the use of different sources, human or nonhuman, organized in a systematic process in the digital age. Connectivisn Theory (Siemens, 2005) focuses on organizational knowledge and transference of learning to students by understanding the flow of social network in distance learning. This includes the parents that play a vital role in supporting their children. With the challenges and difficulties that the parents are experiencing, there are disruptions in the organizational system to support or deliver learning to students. It is necessary that learning inequalities, negative impact to mental, behavioural, and physical health, and putting additional burden to parent's responsibilities be addressed by a social network among students, teachers, community, and educational sectors.

\section{Conclusion}

With the implementation of education during the pandemic, parents' struggles include disruptions of their schedule, inadequate skills, and financial difficulties. With these; learning inequalities, negative impact to mental, behavioral, physical health, and additional burden to parents are evident. To address these issues, 
there should be collaboration among students, adequate teacher support, community involvement, and an adaptive educational framework.

\section{Recommendation}

This study is limited to five studies that fit the selection criteria based on the focus of interest. Thus, it is suggested that inclusion of additional studies concerning other factors be included. This would make a more comprehensive understanding on the underlying factors that affect education during pandemic.

\section{References}

Abuhammad, S. (2020). Barriers to distance learning during the COVID-19 outbreak: A qualitative review from parents' perspective. Heliyon, e05482.

Agnoletto, R., \& Queiroz, V. (2020). COVID-19 and the challenges in Education. Brazil: Universidade de São Paulo.

Allen, J., Rowan, L., \& Singh, P. (2020). Teaching and teacher education in the time of COVID-19.

Aristovnik, A., Keržič, D., Ravšelj, D., Tomaževič, N., \& Umek, L. (2020). Impacts of the COVID-19 pandemic on life of higher education students: A global perspective. Sustainability, 12(20), 8438.

Bloom, D. A., Reid, J. R., \& Cassady, C. I. (2020). Education in the time of COVID-19. Pediatric Radiology, 50, $1055-1058$.

Bonal, X., \& González, S. (2020). The impact of lockdown on the learning gap: family and school divisions in times of crisis. International Review of Education, 1-21.

Burgess, S., \& Sievertsen, H. H. (2020). Schools, skills, and learning: The impact of COVID-19 on education.

Crawford, J., Butler-Henderson, K., Rudolph, J., Malkawi, B., Glowatz, M., Burton, R., ... \& Lam, S. (2020). COVID-19: 20 countries' higher education intra-period digital pedagogy responses. Journal of Applied Learning \& Teaching, 3(1), 1-20.

Daniel, J. (2020). Education and the COVID-19 pandemic. Prospects, 49(1), 91-96.

Dong, C., Cao, S., \& Li, H. (2020). Young children's online learning during COVID-19 pandemic: Chinese parents' beliefs and attitudes. Children and Youth Services Review, 118, 105440.

Garbe, A., Ogurlu, U., Logan, N., \& Cook, P. (2020). Parents' experiences with remote education during COVID-19 school closures. American Journal of Qualitative Research, 4(3), 45-65.

Gonzalez, T., De La Rubia, M. A., Hincz, K. P., Comas-Lopez, M., Subirats, L., Fort, S., \& Sacha, G. M. (2020). Influence of COVID-19 confinement on students' performance in higher education. PloS one, 15(10), e0239490.

Grover, S., Goyal, S. K., Mehra, A., Sahoo, S., \& Goyal, S. (2020). A Survey of Parents of Children Attending the Online Classes During the Ongoing COVID-19 Pandemic. The Indian Journal of Pediatrics, 1-1.

Harris, A. (2020). COVID-19-school leadership in crisis?. Journal of Professional Capital and Community.

Karalis, T., \& Raikou, N. (2020). Teaching at the times of COVID-19: Inferences and Implications for Higher Education Pedagogy. International Journal of Academic Research in Business and Social Sciences, 10(5), 479-493.

Lee, S., Ward, K., Chang, O., \& Downing, K. (2021). Parenting activities and the transition to home-based education during the COVID19 pandemic.

Marinoni, G., Van't Land, H., \& Jensen, T. (2020). The impact of Covid-19 on higher education around the world. IAU Global Survey Report.

Moorhouse, B. L. (2020). Adaptations to a face-to-face initial teacher education course 'forced'online due to the COVID-19 pandemic. Journal of Education for Teaching, 46(4), 609-611.

Paterson, B. L., Thorne, S. E., Canam, C., \& Jillings, C. (2001). Meta-study of qualitative health research: A practical guide to metaanalysis and meta-synthesis (Vol. 3). Sage.

Reimers, F. M., \& Schleicher, A. (2020). A framework to guide an education response to the COVID-19 Pandemic of 2020. OECD. Retrieved April, 14(2020), 2020-04.

Schleicher, A. (2020). The impact of covid-19 on education insights from education at a glance 2020. Retrieved from oecd. org website: https://www. oecd. org/education/the-impact-of-covid-19-on-education-insights-education-at-a-glance-2020. pdf.

Siemens, G. (2005). Connectivism: a theory of learning for the digital age. International journal of instructional technology and distance learning, 2(1), 1-15.

Timulak, L. (2014). Qualitative meta-analysis. The SAGE handbook of qualitative data analysis, 481.

Toquero, C. M. (2020). Challenges and Opportunities for Higher Education Amid the COVID-19 Pandemic: The Philippine Context. Pedagogical Research, 5(4).

Tria, J. Z. (2020). The COVID-19 pandemic through the lens of education in the Philippines: The new normal. International Journal of Pedagogical Development and Lifelong Learning, 1(1), 2-4.

Vlachopoulos, D. (2020). COVID-19: threat or opportunity for online education?. Higher Learning Research Communications, $10(1), 2$.

Zhu, X., \& Liu, J. (2020). Education in and after Covid-19: Immediate responses and long-term visions. Postdigital Science and Education, 2(3), 695-699. 